\title{
Truth and Contradiction in Aristotle's De Interpretatione 6-9
}

\section{Citation}

Jones, Russell Edward. 2010. Truth and contradiction in Aristotle's De Interpretatione 6-9.

Phronesis 55(1): 26-67.

\section{Published Version}

doi:10.1163/003188610X12589452898804

\section{Permanent link}

http://nrs.harvard.edu/urn-3:HUL.InstRepos:10021578

\section{Terms of Use}

This article was downloaded from Harvard University's DASH repository, and is made available under the terms and conditions applicable to Open Access Policy Articles, as set forth at http:// nrs.harvard.edu/urn-3:HUL.InstRepos:dash.current.terms-of-use\#OAP

\section{Share Your Story}

The Harvard community has made this article openly available.

Please share how this access benefits you. Submit a story.

Accessibility 


\title{
Truth and Contradiction in Aristotle's De Interpretatione 6-9
}

\author{
Russell E. Jones \\ Department of Philosophy, University of Oklahoma \\ Norman, OK 73019-2006, USA \\ rustyjones@ou.edu
}

\begin{abstract}
In De Interpretatione 6-9, Aristotle considers three logical principles: the principle of bivalence, the law of excluded middle, and the rule of contradictory pairs (according to which of any contradictory pair of statements, exactly one is true and the other false). Surprisingly, Aristotle accepts none of these without qualification. I offer a coherent interpretation of these chapters as a whole, while focusing special attention on two sorts of statements that are of particular interest to Aristotle: universal statements not made universally and future particular statements. With respect to the former, I argue that Aristotle takes them to be indeterminate and so to violate the rule of contradictory pairs. With respect to the latter, the subject of the much discussed ninth chapter, I argue that the rule of contradictory pairs, and not the principle of bivalence, is the focus of Aristotle's refutation. Nevertheless, Aristotle rejects bivalence for future particular statements.
\end{abstract}

\section{Keywords}

truth, falsehood, contradiction, bivalence, De Interpretatione

Consider the following three principles, each of which Aristotle examines in De Interpretatione 6-9: 
[PB] For every statement $p$, either $p$ is true or $p$ is false.

[LEM] For every contradictory pair $(p, q)$, the following is a necessary truth: 'Either $p$ or $q .{ }^{1}$

[RCP] For every contradictory pair $(p, q)$, one of $p$ and $q$ is true, and the other is false.

It may be difficult at first look to see the differences between these principles. PB ('Principle of Bivalence') stands out as being about single statements, while the other two are about pairs of statements. Given standard modern symbolic logic - i.e., the assumption of PB plus the rules of inference found on the inside cover of most introductory logic books - each of these three principles is either foundational to the system or an easy step up from that foundation. ${ }^{2}$ But if we are building from the ground up - that is, if we are putting together foundational logical principles rather than working within a pre-established set of inference rules - then the truth of these principles remains an open question. Consider, for example, the

\footnotetext{
${ }^{1}$ Throughout, in formulating principles about contradictory pairs I use the ordered pair $(p, q)$ rather than the ordered pair $(p, \sim p)$, though the latter may seem less awkward and more perspicuous. I use the former formulation in order to avoid begging several sorts of questions, including whether Aristotle's conception of negation is internal or external to a proposition, and whether contradictory pairs behave like a truth-table including $p$ and $\sim p$ would lead us to expect. These and related questions will be discussed in some detail throughout the essay. In some cases, when the alternative seems too awkward, I use terms of the form notp. Again, I do not intend to decide in advance whether ' $n o t$-' in these cases functions exactly like the modern symbol ' '.

${ }^{2}$ Indeed, my elementary logic students (at least those with passing grades) would readily and rightly assent to all three propositions. For they have learned that every statement can be assigned one of two truth values (true or false), and this is just what PB claims; and they can construct truth tables for negations, conjunctions, disjunctions, and conditionals, from which (in conjunction with PB) the other two propositions follow. It is a major task of this paper to show that Aristotle does not treat these propositions in precisely the same way as someone steeped in modern symbolic logic is likely to treat them.
} 
supervaluationist logic that has been articulated and gained some currency in recent decades. ${ }^{3} \mathrm{~A}$ rough characterization of the supervaluationist account of truth is as follows: $p$ is now true (in the relevant sense) just in case, for any way the world could go in the future, the complete history of the world includes $p$. So, the statement 'I will walk my dog tomorrow' is true now just in case every possible way the world could go from here includes my walking my dog tomorrow.

Likewise for the statements 'The Treaty of Versailles was signed in 1919' and 'There will never be a round square'. The latter two statements are true on this criterion, but the first statement is not. But 'I will walk my dog tomorrow' is not false, for my dog and I may well take our customary walk in the morning. The statement is neither true nor false, then, and so PB does not hold on this criterion. Nevertheless, LEM ('Law of Excluded Middle') holds. For example, the disjunctive statement 'I will walk my dog tomorrow or I will not walk my dog tomorrow' is true even though neither of its disjuncts is, for there is no possible way the world could go from here such that I neither walk my dog nor fail to walk her. So, supervaluationism endorses LEM, but not PB. Like PB, RCP ('Rule of Contradictory Pairs') does not hold on the supervaluationist account. For 'I will walk my dog tomorrow' and 'I will not walk my dog tomorrow' form a contradictory pair, yet it is not the case that one of the pair is true and the other false. It is important to be clear about this, for it shows that RCP and LEM are distinct principles and prepares us to find Aristotle treating them differently in De Interpretatione. ${ }^{4}$

\footnotetext{
${ }^{3}$ See, for example, the early formulation of supervaluationism in R. H. Thomason's 'Indeterminist Time and Truth-Value Gaps', Theoria 36 (1970), 264-281.

${ }^{4}$ The merits of supervaluationism have been much discussed in recent years. As I will suggest that Aristotle's logic shares some of the important and distinctive characteristics of supervaluationism, and since I do not wish to attribute radically implausible views to Aristotle, some readers might expect me to defend supervaluationism against some forceful criticisms that may also apply to Aristotle as I interpret him. But I will neither endorse nor reject supervaluationism in this essay. Charity demands not that we attribute to Aristotle views that are correct, but rather that we attribute to him views that have a reasonable
} 
Aristotle is widely considered to be the first systematic logician. Since he was working on the front end of logical theory, we should not be surprised to find him making an extended effort to get clear on some principles that we are likely to take for granted as foundational. In this paper, I argue based on a close reading of De Interpretatione 6-9 that Aristotle holds none of PB, LEM, and RCP without qualification. Each fails to hold of certain types of statements. For readers unfamiliar with the nuances of De Interpretatione - and perhaps even for some who have read the text carefully - this will no doubt come as a surprise. Perhaps such readers will be tempted to write off Aristotle's arguments if they lead to such conclusions. That would be too hasty, however, and I will show that Aristotle has good reason to deny the unqualified versions of these principles. Many readers will have encountered arguments that Aristotle believes that PB requires restriction, for it has been traditional to read Int. 9 as denying PB with respect to future

degree of plausibility, so far as is consistent with textual and other considerations. And the important characteristics that Aristotle shares with defenders of supervaluationism meet this standard.

Among the charges that have been leveled against supervaluationism are the following. (1) Tarski's T-schema, according to which ' $p$ ' is true if and only if $p$, is violated on supervaluationism. But the T-schema is often taken to be fundamental to the concept of truth. (2) Related to the first charge, on supervaluationism, the truth of a disjunction does not entail that one or the other of the disjuncts is true. (3) Some rules of inference, including conditional proof and reductio ad absurdum, are not preserved in supervaluationism. The first two of these charges are particularly relevant to Aristotle, as will become clear in the discussion of De Interpretatione 9 (on which see $\S 3$, below). Rosanna Keefe (Theories of Vagueness, Cambridge University Press, 2000) has recently offered a thorough defense of supervaluationism against these and other charges. For the debate, I refer the reader to Keefe, especially chapters 7-8. For our purposes, it is enough to note that the current state of the debate shows that supervaluationism is neither obviously false nor wildly implausible, and likewise neither is the position which I will attribute to Aristotle. Whether it is best all things considered is well beyond the scope of this paper. 
contingents. I agree with the tradition in this respect, though the argument structure I identify is importantly different from traditional reconstructions. Others who have done more extensive work on De Interpretatione in general may not be surprised to find RCP up for consideration, as the most recent English monograph on De Interpretatione, by C.W.A. Whitaker, argues that Aristotle raises a variety of counterexamples to RCP. ${ }^{5}$ In this I agree with Whitaker, but again I think the details of Aristotle's arguments remain unaccounted for by Whitaker's interpretation in interesting and important respects. In particular, Whitaker argues that Aristotle accepts PB. I will argue that a careful reading of chapter 9 reveals that Aristotle rejects PB. The interpretation I offer of De Interpretatione 6-9 sheds new light on these important theses, revealing a motivated and coherent Aristotelian account on which he accepts none of these unqualifiedly. These chapters constitute an exploration into the nature of contradiction, a foundational topic for philosophy. Aristotle proceeds in ways importantly different from logicians today, and getting straight on what he is doing in De Interpretatione 6-9 will have implications for other aspects of Aristotelian philosophy.

My interpretation will proceed in three main stages, the first treating chapters 6 and 7 , and the second and third treating chapters 8 and 9, respectively. Chapters 6 and 7 provide much of the groundwork from which the arguments of Int. 6-9 proceed, for there Aristotle discusses the nature of the contradictory pairs which figure in two of the three principles under consideration. In each of the three stages, Aristotle raises a counterexample to RCP. The first counterexample, in chapter 7 , is limited to RCP. The second, in chapter 8 , serves as a counterexample not only to RCP but also to LEM. And the third counterexample, in chapter 9, serves as a counterexample not only to RCP but also to PB.

\section{Contradictory pairs and entailment in Int. 6-7}

\footnotetext{
${ }^{5}$ Aristotle's De Interpretatione: Contradiction and Dialectic (Oxford: Clarendon Press, 1996).
} 
In De Interpretatione 6-7, Aristotle introduces the notion of contradictory pairs. He first reminds us of the two types of statements there are: affirmations and negations (or denials ${ }^{6}$ ). He then gives an argument that for every affirmation there is a corresponding negation, and likewise for every negation there is a corresponding affirmation. A pair of such corresponding statements - one affirmation and its corresponding negation - constitutes a contradictory pair. Aristotle then reclassifies statements into three kinds: those that are about particulars, those that are about universals and are made universally, and those that are about universals but are not made universally. Contradictory pairs behave differently depending on the nature of the statements that compose them. Of particular interest in this context, while most contradictory pairs obey RCP, those that consist of universal statements not made universally form a counterexample to RCP.

Our treatment of Int. 6-7 falls into three parts. The first two - concerning the nature of contradictory pairs and the first two sorts of statements, respectively - can be treated with relative brevity. The third sort of statements, however, presents special problems and requires a more detailed analysis.

\subsection{Contradictory pairs}

Aristotle opens Int. 6 with two definitions, already arrived at in chapter five:

An affirmation is a statement stating something of something, and a negation is a

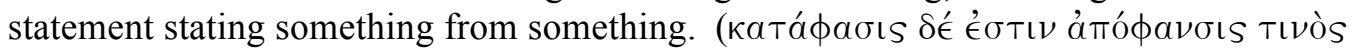

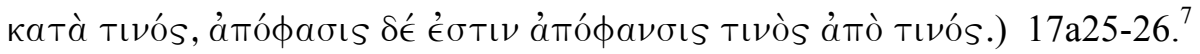

Aristotle has in mind the following analysis of statements. Every statement is composed of two things: a subject and a predicate. Subjects and predicates can stand in either of two relations to one another: they can be combined, and they can be separated. An affirmation states of a subject and a predicate that they are combined (

\footnotetext{
${ }^{6}$ Sometimes it seems more natural to use 'denial' rather than 'negation', and I freely interchange the terms.

${ }^{7}$ Translations are my own unless otherwise noted. Throughout I follow Minio-Paluello's OCT edition.
} 
a predicate that they are separated ( seven, 'Socrates is white' expresses a combination: It is an assertion that Socrates and whiteness are combined. 'Socrates is not white' expresses a separation of Socrates and whiteness: It is a denial that Socrates and whiteness are combined.

Combination and separation are not merely linguistic relations between subject terms and predicate terms. Aristotle's argument that every affirmation has a corresponding negation, and vice versa, reveals that actual things can be combined and separated as well. This brief argument runs as follows (17a26-34):

(1) It is possible to state (a) of what holds that it does not hold, (b) of what does not hold that it holds, (c) of what holds that it holds, and (d) of what does not hold that it does not hold.

So, (2) It is possible to deny whatever anyone has affirmed, and to affirm whatever anyone has denied.

So, (3) For every affirmation there is an opposite negation, and for every negation there is an opposite affirmation.

(3) is just a restatement of (2), so the key inference is from (1) to (2). It is clear that the inference is valid only if it is implicitly assumed that the four ways of stating in (1) exhaust the possibilities, and only if for anything that holds or does not hold, it is possible to state that it holds, and possible to state that it does not hold. It is clear enough that we are to take 'stating that it holds' to be equivalent to 'making an affirmation', and 'stating that it does not hold' to be equivalent to 'making a denial'. So, we could restate the argument as follows, making explicit what is merely implicit in the text:

(1) Statements can be divided exhaustively into four classes: statements (a) of what holds that it does not hold, (b) of what does not hold that it holds, (c) of what holds that it holds, and (d) of what does not hold that it does not hold.

So, (2) It is possible to state about exactly two sorts of things: (a) what holds, and (b) what does not hold. (1)

So, (3) It is possible to state in exactly two different manners: (a) that something holds, and (b) that something does not hold. (1)

(4) To state that something holds is to affirm.

(5) To state that something does not hold is to deny.

(6) So, it is possible to state in exactly two different manners: (a) to affirm, and (b) to deny. (3-5)

(7) For anything that holds, it is possible to affirm it, and possible to deny it. 
(8) For anything that does not hold, it is possible to affirm it, and possible to deny it. So, (9) It is possible to deny whatever anyone has affirmed, and to affirm whatever anyone has denied. $(2,7,8)$

So, (10) For every affirmation there is an opposite negation, and for every negation there is an opposite affirmation. (restatement of 9)

The argument can now easily be seen to be very plausible. Since 3-6 do not serve a strictly inferential function in the argument, but serve only to help legitimate the shift in language from 'stating that it holds' and 'stating that it does not hold' to 'affirming' and 'denying', the only premises that drive the argument are (1), (7), and (8). These each appear eminently plausible and so Aristotle's conclusion is established. Since to affirm something is to state that two things are combined (which is to state that they 'hold'), and since things in reality can either hold or not, it seems that Aristotle means us to think of things in reality as either being combined or not. And this is just what we should expect if we have read the Categories (especially Cat. 2), where we find that things are combined just in case the present-in or the said-of relation holds between them. If these relations fail to hold, they are separated.

Aristotle then announces that he will call any pair of affirmations and negations of the

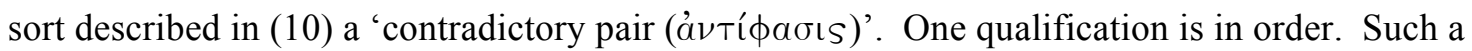
pair of statements is a contradictory pair provided that the terms are "not homonymous, together

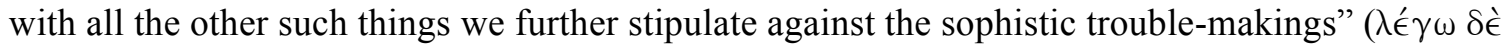

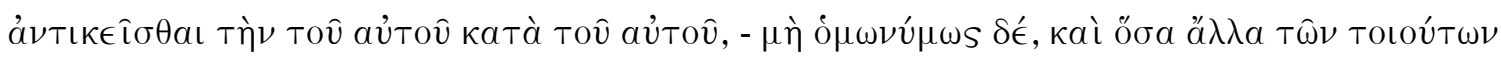

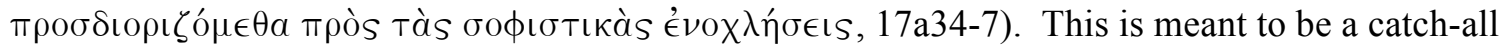
qualification to rule out pairs that trade on homonomy or amphiboly or other funny business of the sort described in the Sophistici Elenchi.

There are three things to note before we move on. First Aristotle does not make use of truth and falsehood in defining contradictory pairs and arguing that every statement is a member of one. This will be important to keep in mind as we approach the following chapters. In particular, since negation for Aristotle is internal to a sentence, it remains an open question 
whether Aristotelian negation will function as modern truth tables would lead us to expect, and whether Aristotelian contradictories will behave in the same way as those defined in terms of the truth and falsehood of their members. ${ }^{8}$

Second, to return to the point made above, the argument makes clear that Aristotle takes the relations between subjects and predicates to mirror the relations between things. After all, one states, for example, of something that holds that it holds. An affirmation is described as stating that something holds. Given what Aristotle told us at the beginning of the chapter about affirmations, this means that to state that something holds is to state that something is кaTá something. But given the similarity of language, this strongly suggests that for something actually to hold just is for something to be кaTá something. And the corresponding account holds for negations.

Finally, the conclusion of the above argument does not explicitly state that every statement belongs to exactly one contradictory pair. For all the argument explicitly tells us, Aristotle may be committed only to the weaker principle that every statement belongs to at least one contradictory pair. But Aristotle does hold the stronger claim. To get an argument for the stronger claim we must look to 7.17b37-18a7, from which we can reconstruct the following argument:

(1) There are only two manners of stating: stating that the subject and predicate are combined (i.e. affirming) and stating that the subject and predicate are separated (i.e. negating).

So, (2) From the same subject and predicate, no more than two statements can be formed: one affirmation and one negation.

(3) A negation must have the same subject and predicate as its corresponding affirmation, and vice versa.

So, (4) No affirmation has more than one corresponding negation, and vice versa $(2,3)$

The argument is plainly valid. We have already seen that Aristotle relies on (1) throughout chapter six. (3) can simply be stipulated, and it is a commonsensical stipulation at that. Conjoin

\footnotetext{
${ }^{8}$ As in Cresswell's definition, below.
} 
the conclusion of the argument with the conclusion of the earlier argument ((10), above), and you have the principle that every statement belongs to exactly one contradictory pair. ${ }^{9}$

The question whether every statement belongs to exactly one contradictory pair is still a live one. M. J. Cresswell gives the following argument that if every proposition has exactly one contradictory, then logically equivalent propositions are identical. ${ }^{10}$ Since ' $2+3=5$ ' and ' $4 \mathrm{x} 7$ $=28^{\prime}$, for example, are logically equivalent but apparently distinct propositions, Cresswell's argument threatens to undermine the principle that every statement has exactly one contradictory (i.e., belongs to exactly one contradictory pair).

(1) Every proposition has exactly one contradictory. (assumed for conditional proof) (2) $p$ and $q$ are contradictories iff: (i) it is not logically possible for both $p$ and $q$ to be true; and (ii) it is logically necessary that at least one of $p$ and $q$ is true. (definition of contradictories)

(3) If $p$ and $q$ are contradictories, then $q$ and $p$ are contradictories. (symmetry of contradictoriness)

(4) Let $p_{1}$ and $p_{2}$ be two propositions which are logically equivalent. (by stipulation)

So, (5) $p_{l}$ has a contradictory $q$. (1)

So, (6) $p_{2}$ and $q$ cannot both be true. $(2 \mathrm{i}, 4,5)$

So, (7) At least one of $p_{2}$ and $q$ must be true. $(2 \mathrm{ii}, 4,5)$

So, (8) $p_{2}$ and $q$ are contradictories. $(2,6,7)$

So, (9) $p_{1}$ is a contradictory of $q$, and $p_{2}$ is a contradictory of $q$. $(5,8)$

So, $(10) p_{1}$ and $p_{2}$ are identical. $(1,9)$

So, (11) If every proposition has exactly one contradictory, then logically equivalent propositions are identical. (1-10, conditional proof)

The argument is valid, and so one might think that since Aristotle accepts the antecedent of (11), he is committed to the consequent. But this would have the counterintuitive consequence, among others, that every mathematical proposition is identical to every other. If my interpretation in the remainder of this paper is correct, however, Aristotle would reject (11) because he would reject

\footnotetext{
${ }^{9}$ Aristotle actually seems to make the stronger claim at $17 \mathrm{~b} 37$ that every statement has exactly one contradictory, but of course at this stage the conclusion of the earlier argument is already on the table.

${ }^{10}$ M. J. Cresswell, 'Does Every Proposition Have a Unique Contradictory?', Analysis 68.2 (April 2008), 112-114. The precise formulation is my own, though this is very much Cresswell's argument.
} 
(2). (2) entails RCP, a principle Aristotle rejects. ${ }^{11}$ But before giving us counterexamples to $\mathrm{RCP}$, Aristotle first examines two sorts of contradictory pairs that obey RCP.

\subsection{Contradictory pairs that obey the rule of contradictory pairs (RCP)}

We have already seen that Aristotle has given two different individually exhaustive classifications of statements: one into two classes (assertions and negations) and one into four (saying of what holds that it holds, or that it does not; and saying of what does not hold that it holds, or that it does not). In Int. 7 he offers a new classification into three classes, and gives the following examples of each:

P statements - about particulars

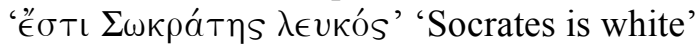

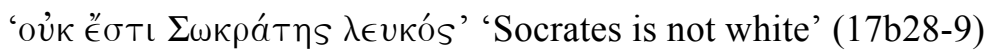

UU statements - about universals, made universally

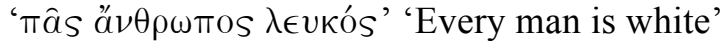

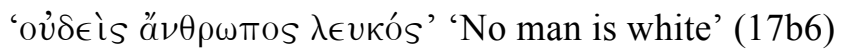

UN statements - about universals, not made universally

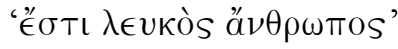

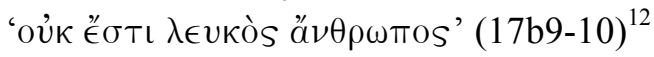

The first two of these, P and UU statements, are relatively easily understood. UN statements will be the focus of the following section.

\footnotetext{
${ }^{11}$ It is noteworthy that while (2) explicitly uses the notion of truth to define contradictories, Aristotle does not.

${ }^{12} \mathrm{UN}$ statements are the focus of the following section. I leave these statements untranslated because any translation would tend to favor one interpretation over another. It will therefore be best to refrain from translating these statements before we have reached some conclusions about their proper interpretation. But a rough working translation, which is meant to be as neutral as possible and simply provides one English word for each Greek word, is 'Man is white' and 'Man is not white'.
} 


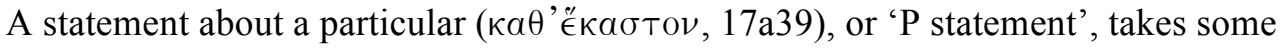
singular item as its subject and predicates something of that subject. The two examples given above form a contradictory pair. A statement made universally about a universal ('́Tì Tô̂

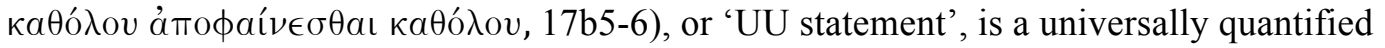
statement. The two examples given above are contraries ('́vavtía ). A contrary pair is a set of two statements: (a) one of which affirms and one denies the same thing of the same thing; (b) both of which may be false but not both true; and (c) whose contradictories may both be true (17b16-26). The following, which we may call 'partial statements' should also be classified with the UU group, as they provide the contradictories for 'Every man is white' and 'No man is white', respectively:

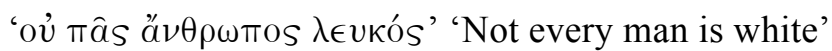

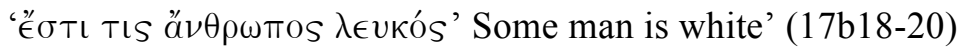

Contradictory pairs which have as one member a UU (or partial) statement have as the other member a partial (or UU) statement.

Recall that RCP is the principle that for every contradictory pair $(p, q)$, one of $p$ and $q$ is true, and the other is false. Unsurprisingly, Aristotle tells us that P statements and UU statements obey this principle: ${ }^{13}$ "So with respect to contradictory pairs about universals taken universally, it

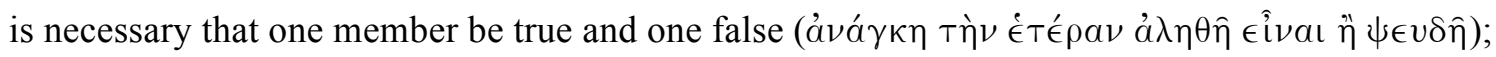
likewise with those about particulars" (17b26-28). What is surprising is that Aristotle goes on to claim that UN statements violate RCP: "But with respect to those about universals not taken

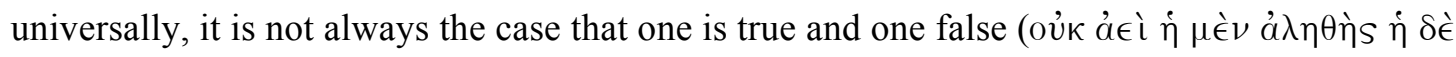
$\psi \in \cup \delta \eta ́ s) "(17 b 29-30)$. To see why this is so we must investigate the nature of UN statements.

\subsection{Universal statements not made universally}

${ }^{13}$ Though he will later qualify this claim with respect to $P$ statements (see $\S 3$, below). 
There has been some dispute in recent scholarship over how to interpret UN statements,

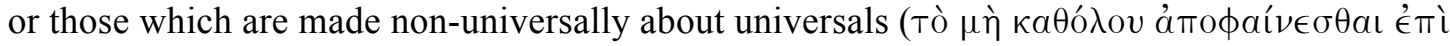

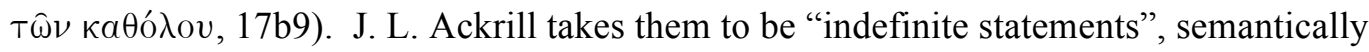
equivalent to 'A man is white' and 'A man is not white', respectively. ${ }^{14}$ On this account, then, such statements function as existentially quantified statements, and so are equivalent to the partial statements of the UU group. C. W. A. Whitaker argues against this interpretation and offers in its place an account according to which these statements are unquantified statements about

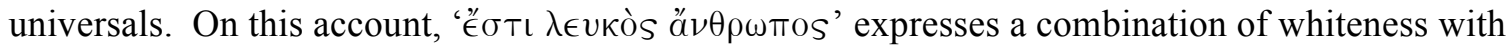
the universal man. ${ }^{15}$

After identifying in Int. 7 six pieces of data for which any satisfactory interpretation must account, I will argue that neither of the two interpretations just mentioned is satisfactory, for each has some consequence that Aristotle clearly cannot accept. On the one hand, Ackrill's interpretation has the absurd consequence that 'A man is not white' is semantically equivalent to 'No man is white'. Whitaker's interpretation, on the other hand, results in a violation of the law of non-contradiction. I then offer an interpretation which has neither of these consequences.

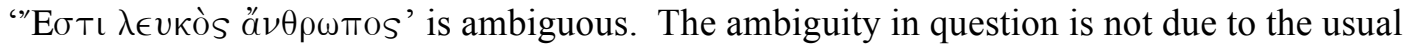
suspects: homonymy and amphiboly. ${ }^{16}$ But it is there nonetheless, and affects the status of this class of statements. This interpretation accounts for all the relevant data.

\subsubsection{The available data}

Aristotle explicitly identifies several characteristics of UN statements. Here I simply list these in the order he presents them, and in what I believe are uncontroversial formulations. It is

\footnotetext{
${ }^{14}$ Aristotle's Categories and De Interpretatione, (Oxford: Oxford University Press, 1963) p. 129.

${ }^{15}$ Whitaker (1996) 83-94.

${ }^{16}$ See, e.g. Int. 17a34-7 and SE 165b30-166a22.
} 
largely with respect to its explanatory power for the data that we should judge each possible interpretation.

(D1) UN statements are not contrary. (17b7-8)

(D2) What is being revealed by UN statements may be contrary. (17b8)

(D3) UN statements are contradictory. (17b26-30)

(D4) For contradictory UN statements, it is not always the case that one is true and one is

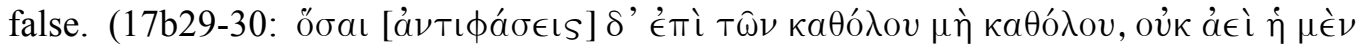

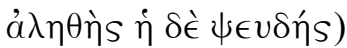

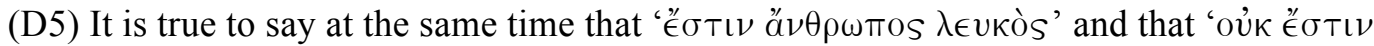

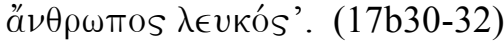

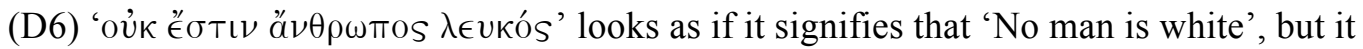
does not signify the same, nor does it necessarily hold at the same time. (17b34-37:

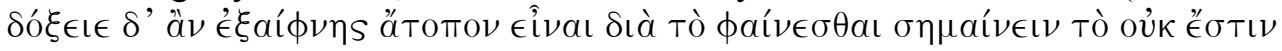

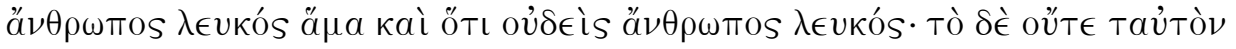

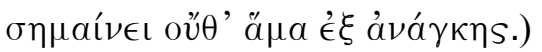

With these pieces of evidence, we are now in a position to evaluate various accounts of UN statements.

\subsubsection{The indefinite account and the universal account}

J. L. Ackrill ${ }^{17}$ takes UN statements to be "indefinite statements". On this interpretation,

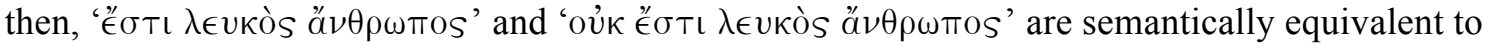
'A man is white' and 'A man is not white', respectively. The former is also semantically

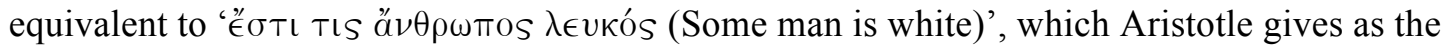

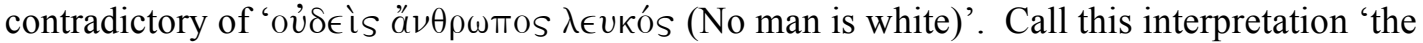
indefinite account'.

${ }^{17} 1963$, p. 129. 
The indefinite account has some initial plausibility, for it is quite natural in Greek to take

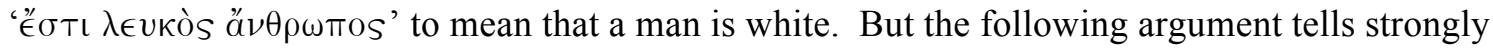
against this interpretation. ${ }^{18}$

(1) The distinctive part of the indefinite account (assumed for reductio), broken into two conjuncts:

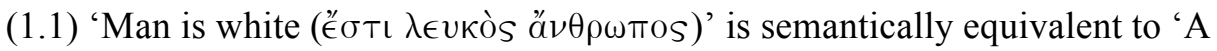
man is white'. ${ }^{19}$

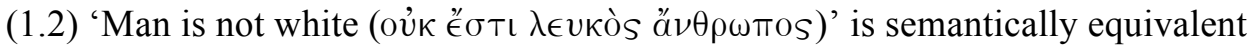
to 'A man is not white'.

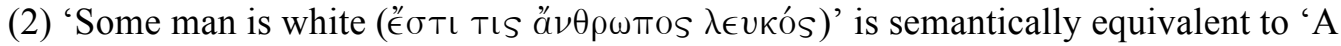
man is white'. (17b19-20)

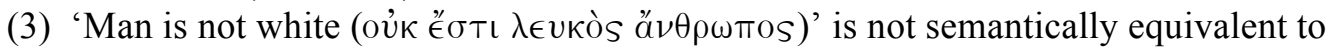

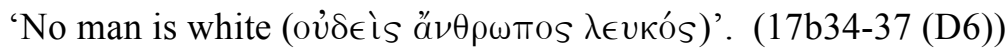

(4) 'Man is white' is contradictory to 'Man is not white'. (17b29-32)

(5) 'No man is white' is contradictory to 'Some man is white'. (17b19-20)

(6) $p$ and $q$ are semantically equivalent just in case there is some $r$ such that $p$ is contradictory to $r$ and $q$ is contradictory to $r$. (17a26-7; 17b37-18a12)

So, (7) 'Man is not white' is contradictory to 'A man is white'. $(1.1,4,6)$

So, (8) 'Man is not white' is contradictory to 'Some man is white'. $(2,6,7)$

So, (9) 'Man is not white' is semantically equivalent to 'No man is white'. $(5,6,8)$

So, (10) The indefinite account is false. (3,9, reductio ad absurdum)

One step in the argument deserves explication. As we have seen, Aristotle clearly holds that there is exactly one contradictory for every statement. So, if $p$ and $q$ have the same contradictory, then they must be semantically equivalent. That is to say, they amount to the same statement. Conversely, if $r$ has as contradictories both $p$ and $q$, then $p$ and $q$ must be semantically equivalent and amount to the same statement, for again $r$ has exactly one contradictory. So, (6) is

\footnotetext{
${ }^{18}$ For a similar argument against the indefinite account, see Whitaker (1996, pp. 86-7).

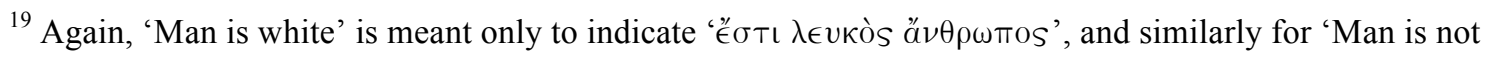

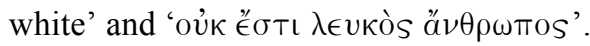


clearly an Aristotelian premise. ${ }^{20}$ The argument, then, goes through straightforwardly, and the indefinite account must be rejected. Not only is (9) highly implausible in itself, but it is an explicit denial of one of the data, (D6), for which an adequate interpretation must account. Since premises (2)-(6) are clearly Aristotelian and even apparently accepted by Ackrill, and since their conjunction with the indefinite account is incoherent, it is clear that the indefinite account must be rejected. Indeed, the distinctive premises of the indefinite account, (1.1) and (1.2), come as a package deal, and so both must be rejected.

Whitaker rightly rejects the indefinite account. He understands UN statements as unquantified statements about universals. That is, the subject of a UN statement is simply a universal, such as 'man' or 'animal', and UN statements are not quantified either universally (as are UU statements) or existentially (as Ackrill takes UN statements). ${ }^{21}$ So, UN statements closely resemble P statements, except that $\mathrm{P}$ statements have a particular as subject, while UN statements

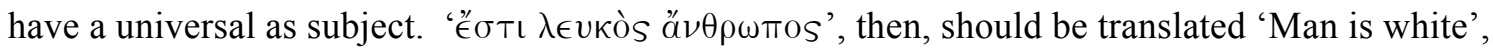
where 'man' refers to a universal. A universal can have contrary properties in virtue of the properties of its particular instantiations, and so 'Man is white' and 'Man is not white' may be true at the same time. For UN contradictory pairs, then, it is possible for both members to be true. Call this 'the universal account'.

The universal account fares no better than the indefinite account. Consider the following argument, keeping in mind that 'man' refers to a universal, throughout.

(1) It is possible for 'Man is white' and 'Man is not white' to be a genuine contradictory pair and true at the same time. (The universal account, assumed for reductio)

(2) If they are true at the same time, either man is white and not white in the same respect, or in different respects. (Law of excluded middle)

\footnotetext{
${ }^{20}$ Also, Ackrill (1963, p. 129) explicitly states that Aristotle could have entirely avoided discussion of

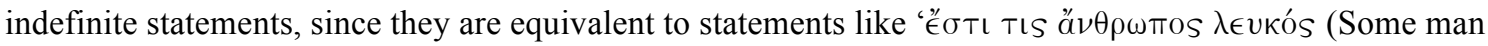
is white)'. So he seems to be committed to something very much like (6).

${ }^{21}$ Whitaker 1996, pp. 83-94.
} 
(3) If in different respects, then 'Man is white' and 'Man is not white' do not constitute a genuine contradictory pair. $\left(17 \mathrm{a} 34-7^{22}\right)$

(4) So, man is white and not white in the same respect. $(2,3)$

(5) If man is white and not white in the same respect, then the law of non-contradiction is violated. (Def. of law of non-contradiction: Metaphysics $1005 \mathrm{~b} 19-20^{23}$ )

(6) So, it is not possible for 'Man is white' and 'Man is not white' to be true together and to be a genuine contradictory pair. (1-5, reductio ad absurdum)

This argument seems to go through straightforwardly. ${ }^{24}$ But recall that part of the universal account is that universals are funny entities, and that a universal has a property just in case one of its instances has that property. We can distinguish between not-being white and being not-white. If a universal has the property of being white, it follows that it does not have the property of not-being white. But it does not also follow that it does not have the property of

22 "I mean they are opposite when they affirm and deny the same thing of the same thing, not homonymously, together with all the other such things we further stipulate against the sophistic troublemakings." Again (see §1.1), this qualification is meant to rule out cases - among others - where something is one way in one respect (say, white of tooth) but a different way in a different respect (say, black of skin). 23 "So it is clear that such is the most certain principle of all ... [that] it is impossible for the same thing to hold and not hold of the same thing in the same respect" (Metaphysics1005b17-20).

${ }^{24}$ Though an anonymous referee asks, "If the phrase 'a universal has a property' is defined as just another way of saying 'some instance of the universal has that property', why does Whitaker's universal account violate the law of non-contradiction?" To clarify, I do not think it would violate the law of noncontradiction, were this what Whitaker meant. But I take Whitaker to mean something importantly different. If all he means is that $\mathrm{UN}$ statements express the notion that some instance of a given universal has a given property, then my argument does not apply to Whitaker's true view. But in this case, I fail to see how Whitaker's interpretation differs in any important way from Ackrill's, and so the argument against Ackrill's view would apply to Whitaker's as well. Since Whitaker himself argues against Ackrill's view, I think we should take him to be saying something rather different: that UN statements are genuinely about universals, rather than instances of universals. What is true of a universal may be true in virtue of its instances, but it is nevertheless the universals, rather than their instances, which are the subjects of UN statements. 
being not-white. So, if some man is white, and some man is not white, then the universal 'man' has both the property of being white and the property of being not-white. And this is not a violation of the law of non-contradiction, but merely an interesting fact about a universal. ${ }^{25}$

This line of reasoning is not available as an interpretation of De Interpretatione, however. Aristotle clearly distinguishes between negations, or negated verbs (for example, 'is-not'), and negative properties (for example, 'not-white'), by means of word order. In the former case, the negative particle is typically placed immediately before the verb. In the latter case, the negative particle is typically placed immediately before the predicate. ${ }^{26}$ But in 'oúk é $\sigma \tau \iota ~ \lambda \epsilon \cup \kappa o ̀ s$ $\alpha^{\prime} \nu \theta \rho \omega \pi \mathrm{s}^{\prime}$, the negative particle is placed before the verb, strongly suggesting that we should understand the verb to be negated, 'is-not white', rather than a negative predicate, 'is not-white'. So, the argument against this interpretation appears to be decisive.

\subsubsection{UN statements as indeterminate}

${ }^{25}$ Whitaker (1996, pp. 91-3) seems to take an even more extreme position than this. On his view, man can both be white and not-be white, where the negation is understood to go with the verb. But this view seems clearly to violate the law of non-contradiction, a bedrock of Aristotle's philosophy, and so to be a nonstarter. In articulating the position as affirming that man can be both white and not-white, where being notwhite does not entail not-being white, I have attempted to present a position with greater initial plausibility. However, I do not mean to endorse it as anything but initially more plausible than the extreme position, as I am quite sure that even the more moderate position is not consistent with De Interpretatione (see below).

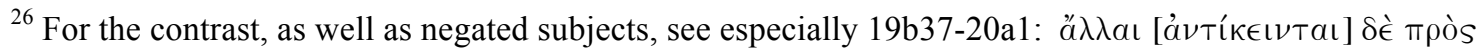

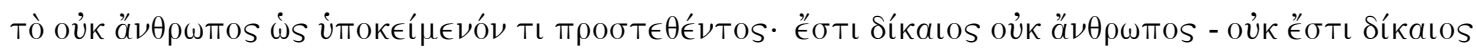

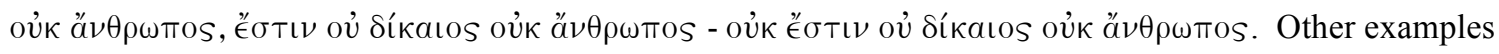
of negated verbs and negative predicates occur, among other places, at 19b27-30 and 20a31-6. 
The need for an alternative to the two foregoing interpretations is apparent. In this section I articulate and defend such an alternative. My interpretation takes its inspiration from (D1) and (D2): UN statements are not contrary, but what is being revealed by them may be contrary. This suggests that there is an ambiguity in UN statements. Though they are, strictly speaking, not contraries, since they are not UU statements, nevertheless what they reveal may be contrary; i.e., UN statements may be used to convey the same thing as UU statements. But (D6) makes plain that even if they may convey the same thing as UU statements, they are not semantically equivalent to UU statements. This, I suggest, is because UN statements are indeterminate. They may be used to convey the same thing as UU statements or the same thing as existentially quantified statements, the contraries of UU statements. How they are understood in a given instance will determine whether or not they are genuinely contradictory in that

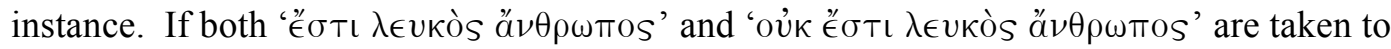
convey the same thing as UU statements, it will be possible for both to be false. For in this instance they will form a contrary pair, and one feature of contrary pairs is that it is possible for both members to be false. If both are taken to convey the same thing as the contradictories of UU statements, partial statements, then it will be possible for both to be true. For it is possible for some man to be white and some man not to be white, at the same time and in the same respect. If, however, one is taken as a UU statement and one as a partial statement, then one will be true and one false.

The ambiguity is especially pronounced because of the lack of an indefinite article in Greek. While the indefinite pronoun 'TIS' can serve a similar function, as in 'ÉOTI TIS ă $\nu \theta \rho \omega \pi$ os $\lambda \epsilon \cup \kappa o ́ s '$, it is more common in Greek to omit article and pronoun altogether to convey what in English we convey with 'a' and 'some'. But omitting the article and pronoun leaves one with a statement that could also plausibly be taken to convey that man is white by nature, or that all men are white. So, in Greek, UN statements are ambiguous in a way that affects whether in a 
given case they form a genuine contradictory pair. Call this interpretation 'the indeterminacy account'.

This very name for the account suggests a response to an objection that may arise. An objector may challenge this interpretation using the very data which inspired it. After all, (D1) says that UN statements are not contrary. But my interpretation is committed to treating them as contrary, sometimes at any rate. Does not my interpretation violate (D1), then?

It does not. According to the indeterminacy account, Aristotle is here treating UN statements as just that, indeterminate. Prior to being used by a speaker to convey something determinate, they are importantly distinct from both UU statements and indefinite statements. After all, if they are capable of conveying a broader range of meanings than either UU statements or indefinite statements, they can hardly be strictly equivalent to either of these. It is only once they are used to convey something determinate that they take on the characteristics of these other classes of statements. Since contrary pairs by definition have members both of which may be false but not both true, and since under some determinations UN statements could both be true, considered as indeterminate UN statements are not contraries.

But, our objector may respond, this is incompatible with (D5), which states that it is true

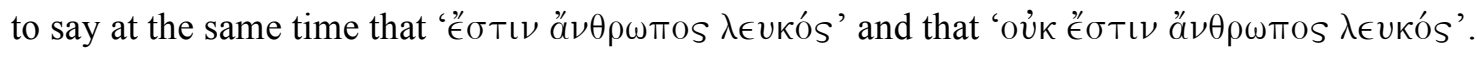
Surely if Aristotle says that these can be true together, then he cannot be considering them in their indeterminate form. But the answer to this is quite straightforward as well. Aristotle is revealing that among the possible things that UN statements can convey are those that indefinite statements convey. So, a contradictory pair of UN statements may convey things that can be true together.

A final worry about the indeterminacy account may arise. At the end of chapter 6 Aristotle seems to rule out that ambiguous statements are under consideration, a point I rely on in arguing against Whitaker's universal account. A contradictory pair is a set of two statements, one of which affirms and one of which denies the same thing of the same thing, provided that the 
terms are "not homonymous, together with all the other such things we further stipulate against the sophistic trouble-makings" (17a34-7). "All the other such things we further stipulate" could easily be taken to include ambiguity quite generally. So it appears that ambiguity is not an available interpretation, and so the indeterminacy account is false.

This worry is surmountable as well. 17a34-7 explicitly rules out cases of homonymy. In the Sophistici Elenchi Aristotle discusses such cases at 165b30-166a7. Also in SE, Aristotle discusses cases of amphiboly (166a7-22). But it is not clear that he has other cases of ambiguity in mind, either in Int. or $S E{ }^{27}$ And UN statements need not contain either homonymy or amphiboly in order to be ambiguous. The ambiguity arises instead from the possible intentions of a speaker who utters this sentence. A UN statement may be used to convey different thoughts.

UN statements, then, present an odd case. Like statements containing homonymy and amphiboly, they are ambiguous. But unlike statements containing homonymy and amphiboly, there is no particular word meaning or grammatical structure of a UN statement to which we can attribute the ambiguity. Rather, it is the variety of things a speaker may intend to reveal by uttering a UN statement that makes it ambiguous. In this respect, UN statements are similar to statements like 'Johnny is ready' and 'Steel is strong enough.' Nowadays, some philosophers of language take such statements, though grammatically complete, to fail to express a proposition

\footnotetext{
${ }^{27}$ Indeterminacy of the sort I am attributing to UN statements does not fit well within any of the six types of fallacies dependent on language: homonymy, amphiboly, collection, division, accent, and form of speech. (For the list, see $S E 165 \mathrm{~b} 26-8$. For discussion of each of the six types, see165b23-166b19.) Even if this sort of indeterminacy were in view in $S E$, however, this would not disqualify the indeterminacy account. For Int. 8 treats statements which are syntactically one but semantically many, and such statements would seem to fall under the category of 'fallacies concerning making two questions one' treated at $S E 167 \mathrm{~b} 37-168 \mathrm{a} 17$. On this see $\S 2$, below. So if a way is discovered to fit indeterminate statements into the treatment of fallacy in $S E$, it will not automatically follow that UN statements in Int. 7 cannot be understood as indeterminate.
} 
absent a context. Likewise, UN statements fail to have a determinate meaning absent a context, though they are grammatically complete and can be grouped into contradictory pairs. So, Aristotle takes these statements to conform to the principle at 17a34-7: one of each contradictory pair affirms and one denies the same thing of the same thing, and the terms are "not homonymous, together with all the other such things we further stipulate against the sophistic trouble-makings." Nevertheless, these statements are indeterminate as to what their utterance is meant to convey. Sometimes, both members of the pair will be meant to convey what UU statements would, sometimes both will be meant to convey what partial statements would, and sometimes one has the meaning of a UU statement and the other of a partial statement. But what the statements are meant to convey is undetermined by their form or syntax. And so, when considered in their indeterminate form, it is possible that both are true, it is possible that both are false, and it is possible that one is true and the other false. Since UN statements are in themselves indeterminate with respect to these possibilities, they are not in their indeterminate form to be taken as genuine contradictories.

My interpretation can account for every relevant piece of data identified in section 1:

(D1) UN statements are not contrary.

(D2) What is being revealed by UN statements may be contrary.

(D3) UN statements are contradictory.

(D4) For contradictory UN statements, it is not always the case that one is true and one is false.

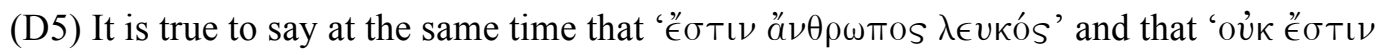

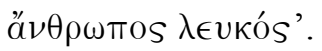

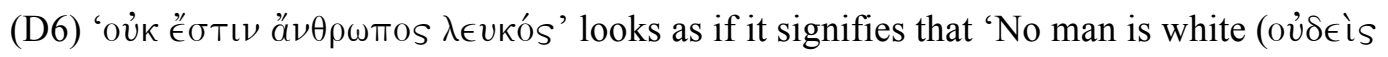
$\ddot{\alpha} \nu \theta \rho \omega \pi \operatorname{sos} \lambda \epsilon \cup \kappa o ́ s) '$, but it does not signify the same, nor does it necessarily hold at the same time.

Under some determinations, UN statements will be true together. This accounts for (D1), (D4), and (D5). (D2) is very well supported by my interpretation, since it is a central feature of my interpretation that UN statements may be used to reveal various things, including the same things as UU statements. (D3) is, of course, accounted for, for UN statements are contradictory. Indeed, under some, but not all, determinations, contradictory pairs consisting of UN statements will be 
such that one must be true and one false. And (D6) is accounted for, because even though one of

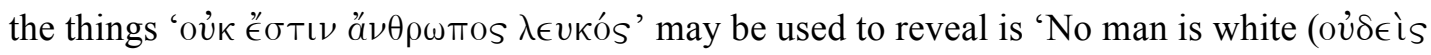
$\ddot{\alpha} \nu \theta \rho \omega \pi$ os $\lambda \epsilon \cup \kappa o ́ s) '$, nevertheless the former is indeterminate, while the latter is determinate. In themselves, then, they are not equivalent, since the former can be used to reveal a wider variety of things than the latter.

Finally, it is worth asking why Aristotle would allow indeterminate UN statements to form contradictory pairs at all. Why does he not simply say that such statements are not wellformed until they are used in a determinate way? After all, in chapter five he says that a single statement is "one which reveals one thing ( $(\dot{O} \ddot{c} \nu \delta \eta \lambda \hat{\omega} \nu)$ " (17a16). Since an indeterminate UN statement may reveal more than one thing, it does not appear to meet this criterion for being single and so does not appear to be a candidate for a contradictory pair.

Curiously though, in chapter five Aristotle gives a disjunctive rather than a simple criterion for being a single statement: "[a] one which reveals one thing or [b] one which is one by

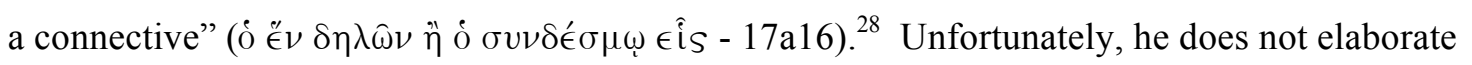
much, especially as it seems that $[\mathrm{a}]$ and $[\mathrm{b}]$ applied separately could yield contrary judgments for the same sentence: for example, 'Socrates is Plato's teacher and in the Lyceum'. But it seems at least that $[\mathrm{a}]$ is a semantic criterion, while $[\mathrm{b}]$ is a syntactic criterion. 'Socrates is Plato's teacher and in the Lyceum' is semantically many but syntactically one. ${ }^{29}$ Aristotle never explicitly

\footnotetext{
${ }^{28}$ For further discussion see Whitaker (1996) 74-77 and Ackrill (1963) 125-127.

${ }^{29}$ One might think that the disjunctive criterion allows for merely syntactic unity only in cases where there is a connective such as ' $\kappa a$ ', and hence that the UN statements we have been considering cannot be a merely syntactic unity. But, considered apart from the disjunctive criterion, they certainly seem to be a syntactic unity. And given that we have little elaboration to go on, [b] is plausibly read as indicating that a statement is syntactically one if (but not only if) it coherently expresses a combination or separation between subject and verb and cannot be made into two by the suitable removal of a connective. ('Suitable
} 
resolves whether one of these takes priority over the other. UN statements of the sort we have been considering are semantically many but syntactically one. Aristotle allows them to form contradictory pairs because they are syntactically one, but warns against thinking that they behave like statements that are both syntactically and semantically one. Unlike P statements like 'Socrates is white', UN statements fail to obey RCP, because they are semantically many. This suggests that some P statements that are semantically many but syntactically one fail to obey RCP as well. 'Socrates is Plato's teacher and in the Lyceum' could be false, but its denial could be false as well (given that the denial is meant to express Socrates' separation from both predicates, as it would be on Aristotle's view). ${ }^{30}$ Yet Aristotle never mentions such statements. Why not? I suggest that it is obvious that 'Socrates is Plato's teacher and in the Lyceum' is semantically many. We are not likely to think that we can infallibly infer the truth value of its denial from its truth-value, and vice versa. But this is not so obvious for UN statements, and takes some work to show. At any rate, it is clear from the closing lines of the chapter that Aristotle takes himself to have provided a counterexample to RCP: "It has been said ... that not every contradictory pair is

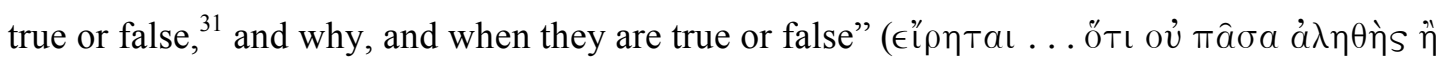

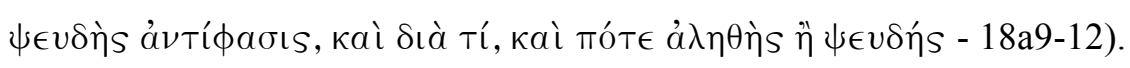

\section{Contradictory pairs, entailment, and excluded middle in Int. 8}

removal' is meant to allow for making 'Socrates is Plato's teacher and in the Lyceum' into 'Socrates is Plato's teacher' and 'Socrates is in the Lyceum'.)

${ }^{30}$ Since both members of such a contradictory pair could be false, this constitutes a counterexample to LEM, as well.

31 "True or false" is clearly shorthand for RCP, as RCP is clearly the target of the chapter. Nothing in the argument suggests that PB is in view, and contradictory pairs taken as a whole cannot have a truth-value; only their members can. 
In Int. 8 we again encounter a class of statements that are syntactically one but semantically many, and again these fail to obey RCP. Furthermore, because both members of the contradictory pairs considered in chapter eight may be false, they constitute a counterexample to LEM, as well. Suppose the word 'cloak' stands for man and horse, not homonymously, but for both at once. 'Cloak' represents two things - man and horse - as a genuine unity, though they are not a unity. ${ }^{32}$ Aristotle argues that 'Cloak is white' - a syntactically single statement - would mean the same thing as this statement with a compound subject: 'Man and horse is white'. But the latter would mean the same thing as the following two statements taken together: 'Man is white' and 'Horse is white'. Since 'Cloak is white' would mean the same thing as the combination of two different semantically single statements, 'Cloak is white' is clearly semantically many. Since it is semantically many, it may violate RCP in a similar way as UN statements. Furthermore, since 'Cloak is white' and 'Cloak is not white' may both be false (for example, if man is white but horse is not), statements where a term represents two things which are not a genuine unity as a unity violate LEM. Recall that LEM is the principle that for every contradictory pair $(p, q)$, the following is a necessary truth: 'Either $p$ or $q$.'

As in chapter seven, Aristotle points out a class of statements which are syntactically one but semantically many, and which thereby fail to obey RCP. Again, because of their syntactic unity, he allows them to form contradictory pairs. And again, the class of statements he raises may hide well the fact that they are semantically many. To be sure, we will not likely be fooled by the example 'Cloak is white'. But any case where one word stands for multiple things which do not form a genuine unity will function the same way, whether a word stands for white and

\footnotetext{
32 'Cloak', then, stands in contrast to 'man', which represents two things - mammal and bipedal - as a unity which really do form a unity. Cf. Int. 11. 'Cloak' also stands in contrast to the English term 'bank', which, though it can be used to represent two different things (sides of rivers and financial institutions), does not represent those things as a unity.
} 
walking, or for tall, dark and handsome, or whatever else one can think of. Again Aristotle sums up the chapter by making clear that he takes himself to have provided a counterexample to RCP: "So neither in these cases is it necessary for one contradictory ${ }^{33}$ to be true and the other false"

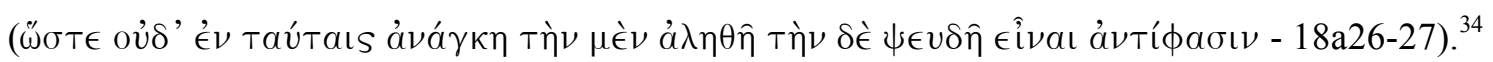

\section{Contradictory pairs and bivalence in Int. 9}

According to the most traditional view of Int. 9, Aristotle denies the fatalist conclusion by denying bivalence, that is, by denying that for any statement, it is either true or it is false. More specifically, he denies an instance of PB:

[PBF] For any statement $p$, where $p$ is about the future, either $p$ is true or $p$ is false.

On this view, the argument structure of Int. 9 is to assume PBF and derive the conclusion that all future events are necessary. But this conclusion is absurd, for it is obvious that some future events are not necessary. So, PBF is rejected. ${ }^{35}$

\footnotetext{
${ }^{33}$ Occasionally Aristotle uses 'á $\nu T i ́ \phi a \sigma ı s$ ' to mean 'contradictory' rather than 'contradictory pair'. It is generally plain in context which he means.

${ }^{34}$ This treatment of Int. 8 is necessarily brief. For further commentary on the details, see Ackrill (1963) 130-132 and Whitaker (1996) 95-108. Another excellent work, which argues that Int. 8 does treat homonomy, is Susanne Bobzien (2008) ‘Aristotle's De Interpretatione 8 is about Ambiguity' (in Maieusis: Essays in Ancient Philosophy in Honour of Myles Burnyeat, ed. Dominic Scott, Oxford University Press, pp. 301-321).

${ }^{35}$ For two among many such interpretations, see Ackrill (1963) 132-142; and Paolo Crivelli, Aristotle on Truth, Cambridge: Cambridge University Press, 2004, esp. 198-233. Others have agreed with the traditional interpretation that the fatalist argument in Int. 9 has this same basic structure of assuming PBF and concluding to the necessity of all future events, but have argued that Aristotle accepts PBF and so cannot avoid the fatalist conclusion by rejecting PBF. Instead, Aristotle identifies a modal fallacy in the
} 
Whitaker has criticized the traditional interpretation. ${ }^{36}$ Whitaker agrees that the argument of the chapter is a reductio, but it is not PBF under attack, but rather the rule of contradictory pairs:

[RCP] For every contradictory pair $(p, q)$, one of $p$ and $q$ is true, and the other is false. An instance of this principle is:

[RCPF] For every contradictory pair $(p, q)$, where both $p$ and $q$ are future particular statements, one of $p$ and $q$ is true, and the other is false.

Chapter nine is set up as a reductio: RCPF is the refutand, and the absurdity to which it leads is the fatalist conclusion. The explanation for RCPF not holding is that, though one of the pair must be true and the other false, it is genuinely indeterminate which is which. There is in principle no correct answer when faced with the question, Will there be a sea-battle tomorrow, or will there not be a sea-battle tomorrow? But, Whitaker maintains, this explanation is consistent with PBF and, in fact, Aristotle holds PBF. According to Whitaker, then, Aristotle accepts the following three propositions:

(1) Reality has yet to determine whether there will be a sea battle tomorrow.

(2) Either a sea battle will occur tomorrow or it will not.

(3) 'A sea battle will occur tomorrow' is either true or it is false, and 'A sea battle will not occur tomorrow' is either true or it is false.

The first makes plain that the matter is genuinely indeterminate; the second expresses Aristotle's commitment to the law of excluded middle even in indeterminate cases; and the third expresses Aristotle's commitment to bivalence, even in indeterminate cases. Whitaker argues that Aristotle accepts these propositions and maintains a coherent position in doing so.

argument, a confusion of necessitas consequentiae and necessitas consequentis. See, e.g., Gail Fine, 'Truth and Necessity in De Interpretatione 9', History of Philosophy Quarterly 1:1 (Jan. 1984), 23-47;

Christopher Shields, Aristotle, 181-191.

${ }^{36}$ Whitaker (1996) 109-131. 
I agree with Whitaker that RCPF is the refutand and the focus of the argument. ${ }^{37}$ Consider the opening lines of Int. 9: "With things that are and things that have been it is

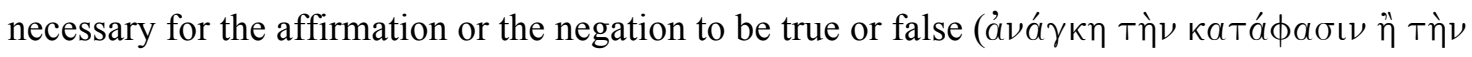

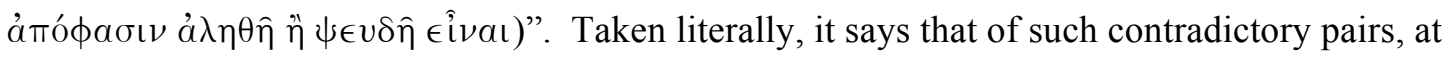
least one member must have a truth-value. But this cannot be Aristotle's meaning. "It is necessary for the affirmation or the negation to be true or false" expresses RCP in shorthand fashion, just as the closing lines of the preceding two chapters express RCP in varying degrees of fullness ("It has been said ... that not every contradictory pair is true or false, and why, and when they are true or false"; "So neither in these cases is it necessary for one contradictory to be true and the other false"). ${ }^{38} \mathrm{RCP}$ (and not PB, as the traditional interpretation would read the opening line) has been the main principle at issue since chapter seven. The opening line of chapter nine is sandwiched directly in between the clear statement of RCP at the end of chapter eight, and a summing up of the results of chapter seven, which concerned RCP: "Also with universals taken

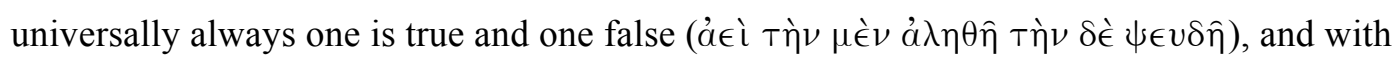
particulars, as has been said; but with universals not said universally it is not necessary. These things have already been discussed" (18a29-33). So when Aristotle then goes directly on to say, "But with particulars that are going to be (

${ }^{37}$ Several of the points made in this paragraph can be found in Whitaker (1996) 112-114.

${ }^{38}$ Aristotle explicitly refers to RCPF as the refutand three other times in Int. 9. The others are at 18b26-31

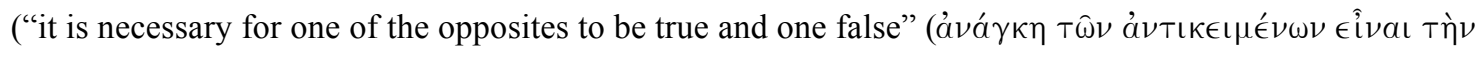

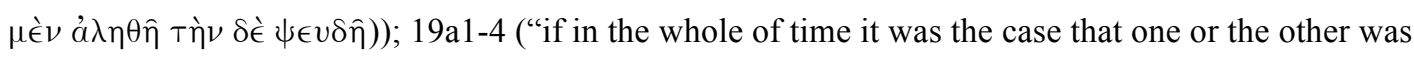

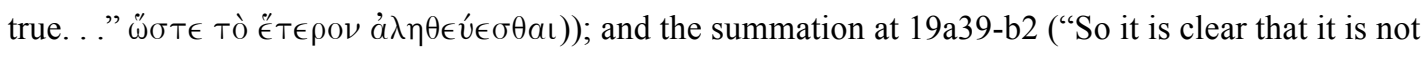
necessary that of every opposing affirmation and negation one is true and one is false" (

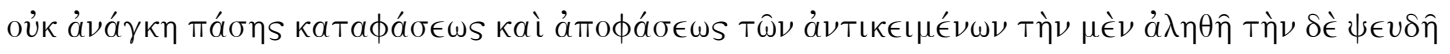

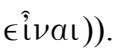


(18a33-34), he is explicitly targeting RCPF. Aristotle is announcing that he will qualify his claim that P statements obey RCP. ${ }^{39}$

This points to a serious error in traditional reconstructions of Aristotle's argument at the very first step: They misidentify the refutand. This error results from a failure to read Int. 9 as intimately connected to the argument of the surrounding chapters, particularly the examination of contradictory pairs and RCP in Int. 6-8. Whitaker, however, falls into another error that is just as serious: Even if Whitaker's argument is persuasive that the traditional identification of the refutand is misguided, he fails to show that the conclusion identified by the traditional interpretation is false. That is, even if RCPF is the refutand, the explanation for it failing to hold for future particular contradictory pairs may be the falsity of PBF. Indeed, there remains very good reason to think that Aristotle denies both RCPF and PBF, for - as I will argue below - on Aristotelian grounds, propositions (1) - (3) (above) are inconsistent. Aristotle clearly expresses his commitment to (1) and (2). He does not clearly express his commitment to (3); indeed, he may well intend Int. 9 to be read as a denial of (3). At any rate, charity demands that we attribute a commitment to (1) - (3) to Aristotle only as a last resort.

Both the traditional error and Whitaker's error are avoidable, and I offer an interpretation which aims to preserve what is particularly valuable about Whitaker's interpretation while retaining the traditional claim that Aristotle rejects bivalence for future particular statements. The development of this new interpretation will proceed in two stages. First, I offer a fresh and independently plausible reconstruction of the argument of the chapter which remains sensitive to both the text of chapter 9 and the rest of Int. by taking RCPF as the refutand, while concluding that Aristotle also rejects PBF. ${ }^{40}$ But Whitaker raises several sorts of evidence for his own view

\footnotetext{
${ }^{39}$ On the initial claim about $\mathrm{P}$ statements see Int. 7 and $§ 1.2$.

${ }^{40}$ It is worth noting that future contingent statements would thereby provide the only counterexamples in Int. 6-9 to any of PB, LEM, or RCP that do not depend on statements that are semantically many.
} 
that Aristotle endorses PBF, which thereby serves as potential evidence against my interpretation. So, after offering my own account, I argue that Whitaker's interpretation is deeply flawed. On the one hand, the positive evidence he gives for his interpretation inconclusive at best, and on the other hand, his interpretation saddles Aristotle with a deeply inconsistent position.

\subsection{The argument of Int. 9}

The main argument of Int. 9 can be understood as a reductio with RCPF as the refutand. In the following, I seek to trace the main line of argument in the chapter. I do not consider everything Aristotle says in the chapter, but only what is directly relevant to the main argument. I then turn to Aristotle's explanatory remarks regarding the main argument.

\subsubsection{The main argument of Int. 9}

Aristotle begins by claiming that RCP holds with respect to statements about the present or the past, both with respect to statements about universals taken universally and with respect to particular statements. But RCP does not hold with respect to universals not taken universally. All of this has been established in chapter seven. Aristotle then announces the thesis of the chapter: With respect to future particulars "it is not the same"; i.e., RCP does not hold with respect to future particulars.

Aristotle immediately launches into his argument. In fact, there are three subarguments (18a34-18b9, 18b9-16, 18b26-19a6), each assuming RCPF and concluding to some absurdity. For the first subargument, assume:

[RCPF] For every contradictory pair $(p, q)$, where both $p$ and $q$ are future particular statements, one of $p$ and $q$ is true, and the other is false.

From RCPF, it follows that:

(4) Either $p$ is true or $q$ is true. (RCPF; 18a35-38) 
Aristotle also explicitly holds a principle connecting truth and a special kind of necessity: ineluctability. If $p$ is ineluctable, there is nothing that can prevent $p$. Notice that whether $p$ is necessary or contingent in this special sense may change from one time to another. For instance, Aristotle seems to endorse the necessity of the present (and almost certainly holds the necessity of the past as well) at 19a23-27. In other words, Aristotle endorses the claim that if $p$ is true now, nothing can change the fact that $p$ is true now. (Likewise, the idea that the past is necessary just is the idea that nothing can now change the fact that an event happened in the past or that a statement was true in the past: i.e., there is no sense crying over spilled milk.) So, if $p$ is a future particular statement, and it is now possible that $p$ and possible that not- $p$, then $p$ is now contingent. But at the time $p$ occurs (or not- $p$ occurs), $p$ (or not- $p$ ) is necessary. It is this kind of necessity as ineluctability that Aristotle has in view throughout the passage. Aristotle holds the following principle (18a39-18b1, 18b9-15):

[TN] If $p$ is true, then $p$ is necessary.

An instantiation of TN yields:

(5) If $q$ is true, then $q$ is necessary. (TN; 18a39-18b1)

And so, the conclusion of the first subargument is:

(6) Either $p$ is necessary or $q$ is necessary. $(4,5 ; 18 \mathrm{~b} 4)$

The argument generalizes for any future particular contradictory pair. So, for any statement, either it or its contradictory is necessary.

The second subargument again makes use of RCPF and TN:

(7) If $p$, then at every time in the past it was true that ' $p$ will be the case'. (RCPF; 18b911)

(8) If at every time in the past it was true that ' $p$ will be the case', then $p$ was always necessary. (TN; 18b11-14)

(9) So, if $p$, then $p$ was always necessary. $(7,8 ; 18 \mathrm{~b} 14-15)$

Following a digression to which we will return, Aristotle offers the third subargument:

(10) If everything that happens is necessary, then there is no need to deliberate or take trouble. (18b26-34)

(11) So, there is no need to deliberate or take trouble. $(6,10$ or 9,10$)$ 
Aristotle takes (6), (9), and (11) to be absurdities, (18b26, 19a7-22). On the one hand, he takes it to be clear that our deliberations and actions can be the origin of things that will be. On the other hand, he takes it as obvious that many things have multiple genuine possibilities. For example, this coat may be destroyed by wear and tear or by scissors; either is a genuine possibility. Not only that, but my deliberation and action can decide which of the possibilities comes about. The falsity of (6), (9), and (11) is far clearer than the truth of the conjunction of the premises that entail them. But which is (are) the offending premise(s)? Aristotle never questions $\mathrm{TN}$, nor does he question (10). Instead, he explicitly and repeatedly identifies RCPF as the refutand (18a28-35, 18b26-31, 19a1-4, 19a39-b2). The conclusion of the main argument of Int. 9 is that RCPF is false.

\subsubsection{Explaining the failure of $R C P F$}

Showing that RCPF is false by showing that it entails falsehoods is different from showing why RCPF is false. Aristotle first precludes two ways of showing why RCPF is false (18b17-25) and then gives his own explanation (19a23-39). The explanation is not very clearly put, and this lack of clarity is a source of confusion for readers. Nevertheless, from Aristotle's clear commitments we can deduce what explanation he is committed to, and we can understand 19a23-39 in a way that is consistent with that explanation.

At 18b17-25, Aristotle precludes two ways of explaining why RCPF fails. Recall that $\mathrm{RCPF}$ is the principle that for any future contradictory pair, exactly one member is true and one is false. Suppose we assume that Aristotle is committed to bivalence for future statements. This seems to leave two ways of explaining the failure of RCPF: either both members of a future contradictory pair may be true, as in the case of universals not taken universally (Int. 7); or both members may be false, as in the case of statements that appear to be about a single thing but are really about multiple things that do not form a unity (Int. 8). 
The second explanation, that both members may be false, is ruled out for two reasons. First, Aristotle initially considers it within the context of the reductio argument, which assumes RCPF. But to say that both members of a future particular contradictory pair are false is to contradict RCPF. So, this response is not available within the context of the reductio (18b17-20): Someone who assumes RCPF should not also say that both members may be false. But second, and more broadly, even once the reductio argument is accepted, this response is not available. For to say, for example, that both members of the contradictory pair concerning the occurrence of a sea battle tomorrow are false is to say that (necessarily) there neither will nor will not be a seabattle tomorrow. But this is a blatant contradiction and a violation of the law of excluded middle (19a27ff; see below). So, it cannot be the case that both members of a future particular contradictory pair are false.

The other explanation, that both members may be true, is ruled out for precisely parallel reasons $(18 \mathrm{~b} 20-22)$. In the context of the reductio argument, it is ruled out because it violates the assumed principle RCPF. But more importantly, to say that both members are true is to say, using the sea battle again, that a sea-battle both will and will not occur tomorrow. But this is again a blatant contradiction. So, it cannot be the case that both members of a future particular contradictory pair are true.

If future particular contradictory pairs can violate RCPF, so that it may not be the case that one member is true and the other false, yet they cannot both be true, nor can they both be false, then it seems that PBF must not hold for future particular statements. For if PBF holds, then every future particular statement is either true or false. Every statement has a contradictory. So, if PBF holds, then the only possible truth values for a future particular contradictory pair $(p, q)$ are $(t, t),(t, f),(f, t)$, and $(f, f)$. Yet Aristotle has ruled out all four of these possibilities. This is strong evidence that Aristotle rejects PBF. Indeed, if Aristotle rejects PBF, he has available a very straightforward explanation of the failure of RCPF: RCPF entails PBF; therefore since PBF 
is false, so is RCPF. Recall that Aristotle is committed to the following extremely plausible principle:

[SC] Every statement has a contradictory. (17a26-34, 17b37-18a12; see §1.1, above.) The argument for PBF follows from RCPF and SC as follows, where $(x, y)$ is any future particular contradictory pair:

(1) For all $x$, if $x$ is a future particular statement, then there is some $y$ such that $(x, y)$ constitutes a future particular contradictory pair. (assumption of SC with respect to future particulars)

(2) For all $x$ and all $y$ such that $x$ and $y$ constitute a future particular contradictory pair $(x, y)$ : (i) $x$ is either true or false; and (ii) if $x$ is true, $y$ is false; and (iii) if $x$ is false, $y$ is true. (assumption of RCPF)

So, (3) For all $x$, if $x$ is a future particular statement, then $x$ is either true or false.

(3) is simply a statement of PBF. In a sense (given the assumption of SC) PBF is

included in RCPF. More broadly, RCP involves an assumption of PB.

Aristotle, then, is committed to rejecting PBF: some statements about the future are

neither true nor false. But is Aristotle aware of this commitment? And does he explicitly identify the falsity of PBF as the explanation for the falsity of RCPF? These are more difficult questions. The argument of 19a23-39, where Aristotle seems to be giving an explanation concerning the main argument $18 \mathrm{a} 28-19 \mathrm{a} 22$, is frustratingly obscure, and seems at many points to admit of several (incompatible) interpretations. Aristotle never says clearly and in so many words that the failure of PBF explains the failure of RCPF. But, 19a23-39 can be plausibly read in such a way that it is not only consistent with such a commitment, but positively supports it. If we were to read 19a23-39 by itself, we would find such a reading possible, but not the only option. But given that we can infer a commitment to denying PBF from other things Aristotle says explicitly, and given that we can read 19a23-39 as consistent with that commitment, charity demands that we do so. With this motivation for my interpretation of 19a23-39, then, I interpret the main points as follows.

Aristotle first distinguishes between necessity of the present and necessity simpliciter. Both types of necessity seem to be versions of necessity as ineluctability (as opposed to, say, 
purely logical necessity). Necessity of the present indicates that something is necessary now; Necessity simpliciter indicates that something is necessary at every time, i.e., the necessity is not qualified by a particular time. That is, given that $S$ is now (for example, a sea battle occurs), $S$ is necessary. But this is not to say that $S$ is necessary simpliciter, for $S$ may have been contingent at some time (19a23-27). Aristotle then endorses the law of excluded middle: for any possible state of affairs $S$, either $S$ or not-S. So, necessarily (simpliciter), either $S$ or not-S. And this applies to future states of affairs just as much as present or past states. But, Aristotle emphasizes, this is not to say that necessarily (simpliciter or qualifiedly) $S$ or necessarily not-S. The modal claim applies only to the disjunction as a whole, not to each of the disjuncts singly. As Aristotle puts it, we cannot "divide" - that is, we cannot distribute the necessity over each of the disjuncts (19a27-32).

Since statements are true or false depending on the way things are in reality, ${ }^{41}$ the same account applies to statements. So, if things in reality are such that $S$ is possible and not-S is possible, the truth-value of the corresponding contradictory statements must reflect these possibilities (19a32-35). This is so for cases where it is not always the case that $S$, nor always the case that $n o t-S$, and $S$ or not-S will obtain in the future; i.e., this is so for future contingent states of affairs (19a35-36). In such cases "it is necessary for one or the other of the contradictories to be true or false - not, however, this one or that one, but as chance has it; or for one to be true rather than the other, yet not already true or false" (19a36-39; Ackrill trans.). In other words, the law of excluded middle holds, for either $S$ will obtain or not-S will obtain, but PBF does not hold, for, again, we cannot "divide" and say either that $S$ will obtain, or that not-S will obtain. ${ }^{42}$

\footnotetext{
${ }^{41}$ Cf. 6.17a26-34, discussed in $§ 1.1$, above.

${ }^{42}$ At this point an objector might point out that on my interpretation Aristotle is committed to denying, first, that Tarski's T-schema (' $\mathrm{p}$ ' is true iff $p$ ) holds universally, and second, that disjunctions are always truth-functional. (See note 4, above.) Again, I refer the reader to Keefe (2000), who, though she is not discussing Aristotle, defends a view similar to the one I attribute to Aristotle. She argues that the central intuitions that support the T-schema and universal truth-functionality for disjunctions can be accounted for
} 
In a sense, I have begged some questions of interpretation concerning 19a23-39, for parts of the text are open to alternative interpretations - though it is worth noting that I think none of these are better supported by the text than mine. But I have not begged the question viciously; there is an argument to support this interpretation. The argument is that, whether he recognizes it or not, it is plain from the first half of chapter 9 that Aristotle is committed to denying PBF. So, charity demands that we see if we can plausibly read 19a23-39 in a way that supports, or is at least consistent with, this commitment. And indeed we can so read the passage, plausibly and without doing any violence to the text at all. This is very strong evidence that this reading is the correct one.

In summary, Int. 9 is primarily concerned with whether future particular contradictory pairs are such that one member is true and one false. The chapter fits well with chapters seven and eight, which ask the same question of other sorts of contradictory pairs. Aristotle gives a reductio argument to show that RCPF does not hold, and this is Aristotle's main point in Int. 9, the one with which he begins (18a28-34) and ends (19a39-19b4) the chapter. But while this shows that RCPF is false, it does little to explain its falsity. If bivalence (PBF) does not hold of future particular statements, that would explain the falsity of RCPF. Arguments that Aristotle accepts PBF are weak, and various explicit statements of Aristotle's commit him to denying PBF. Though Aristotle's explanatory passage at 19a23-39 is obscure, it can plausibly be read in a way that is consistent with, and even supports and makes plain, his commitment to denying PBF. Interpreting Int. 9 in this way avoids two errors of interpretation. First, it avoids the error of reading the chapter as an isolated treatise unconnected to the rest of Int. Treating it that way

on her supervaluationist model, even though she, along with Aristotle, denies that they hold strictly (see especially pp. 213-217). I suggest that Aristotle could have availed himself of Keefe's arguments had he been pressed on this point, and we can do the same on his behalf. Thanks to Mark Wheeler for pressing the objection. 
might lead one mistakenly to identify the refutand as PBF. Second, it avoids the error of thinking that if PBF is not the refutand, then Aristotle does not deny, and is not committed to denying, PBF in Int. 9. Aristotle is so committed, and is most plausibly taken to be explaining the falsity of RCPF by the falsity of PBF.

\subsection{Whitaker on bivalence}

In this section I examine Whitaker's interpretation of Int. 9, namely, that Aristotle denies RCPF but nevertheless accepts PBF. Whitaker gives three main pieces of evidence for his interpretation. I argue, first, that the position Whitaker attributes to Aristotle is inconsistent with central Aristotelian principles. This motivates a careful evaluation of the three pieces of evidence Whitaker gives, since, if strong enough, it will lead us to attributing an inconsistent position to Aristotle. I argue that the evidence he gives for his interpretation is inconclusive at best. Given that we already have a sensible interpretation of the text at hand, that inconclusiveness, coupled with the inconsistency to which it commits Aristotle, gives us sufficient reason to reject Whitaker's interpretation.

\subsubsection{An inconsistent triad}

Recall that on Whitaker's interpretation, Aristotle accepts the following three propositions:

(1) Reality has yet to determine whether there will be a sea battle tomorrow.

(2) Either a sea battle will occur tomorrow or it will not.

(3) 'A sea battle will occur tomorrow' is either true or it is false, and 'A sea battle will not occur tomorrow' is either true or it is false.

Consider the Ockhamist account of truth. According to Ockham, these three propositions are consistent, for on his account, a proposition ' $x$ is (was, will be) $A$ at $t_{m}$ ' is (determinately) true at $t_{n}$, if and only if at some time or other there is (was, will be) no potency in things for $x$ 's not 
being (having been, being going to be) $A$ at $t_{m}$. Conversely, a proposition ' $x$ is (was, will be) $A$ at $t_{m}{ }^{\prime}$ is (determinately) false at $t_{n}$, if and only if at some time or other there is (was, will be) no potency in things for $x$ 's being (having been, being going to be) $A$ at $t_{m} .{ }^{43}$ And at some time (no later than tomorrow), for the proposition 'A sea battle will occur tomorrow', either there will be no potency in things for a sea battle's occurring tomorrow or there will be no potency in things for a sea battle's not occurring tomorrow. If the former, then 'A sea battle will occur tomorrow' is false, and 'A sea battle will not occur tomorrow' is true. If the latter, then these truth-values are reversed. And so one of the statements in (3) will be true now, and one false. (2) follows from this, and (1) is to be taken to mean that at $t_{n}$ (i.e., now) there is a potency in things for a sea battle to occur tomorrow, and there is a potency in things for a sea battle not to occur tomorrow, which contradicts nothing in (2) or (3). So, on an Ockhamist account of truth, the triad is consistent.

It is worth bringing up the Ockhamist account of truth because Aristotle's own account has affinities with Ockham's. There is a historical reason for this: Ockham takes himself to hold Aristotle's account, slightly, but crucially, revised. ${ }^{44}$ The revision is captured by the "at some

\footnotetext{
${ }^{43}$ This formulation is taken from Marilyn McCord Adams's introduction (p. 10) in: William Ockham, Predestination, God's Foreknowledge, and Future Contingents, trans., with introduction, notes, and appendices, by Marilyn McCord Adams and Norman Kretzmann (Indianapolis: Hackett) 1983.

${ }^{44}$ A related difference which I do not discuss here is that Ockham time-indexes statements while Aristotle does not. So, Aristotle, but not Ockham, can allow that statements change in truth-value. See, e.g., Categories 5.4a10-b19, where Aristotle argues that while a statement or belief may have one truth-value at one time and another truth-value at another time, statements and beliefs do not undergo change and are not able to receive contraries. What changes when a statement has a different truth-value at $t_{1}$ than at $t_{2}$ is something in the world to which the statement is related. But this relational change does not produce a change in the statement, any more than Theaetetus growing up and becoming taller than Socrates produces a change in Socrates. What changes is something external to the statement or to Socrates, to which the
} 
time or other". Aristotle's position is that, if a statement is true now, then there is something in reality to which it corresponds now. That is, if ' $\mathrm{x}$ is $A$ ' is true now, then reality is now such that $\mathrm{x}$ is $A$; if 'x will be $A$ at $t_{m}$ ' is true now, then reality is now such that there are no possible futures in which $\mathrm{x}$ is not $A$ at $t_{m}$. And if 'x will be $A$ at $t_{m}{ }^{\prime}$ is false now, then reality is now such that there are no possible futures in which $\mathrm{x}$ is $A$ at $t_{m}$. Ockham interpreted Aristotle as denying truth-value to future contingents because of this account of truth. But Ockham's theological commitments necessitated a commitment to bivalence; otherwise, how could God infallibly foreknow all things, including future contingents? Revising Aristotle's account so that truth is not tied to current reality (and so mutable), but rather to reality at any time (and so immutable), allows Ockham to maintain his theological commitments.

Notice also that it is this revision that makes the triad of (1) - (3) consistent on an Ockhamist correspondence account. For if truth is tied to current reality, then we may again read (1) to mean that at $t_{n}$ there is a potency in things for a sea battle to occur tomorrow, and there is a potency in things for a sea battle not to occur tomorrow. But on the Aristotelian account of truth, it follows from (1) that (3) cannot be the case. If reality is undetermined as to whether there will be a sea battle tomorrow, then it is possible that there will be and possible that there will not. But this means it is neither true or false that a sea battle will occur tomorrow, nor true or false that it will not. So, (1) entails the negation of (3). (2) is consistent with (1) and with (3), but (1) and (3) are inconsistent. $^{45}$

statement or Socrates bears some relation. Being-true and being-taller-than-Theaetetus are not genuine properties of the statement or Socrates, respectively. On this see also Crivelli 2004, 30-31 and 183-194. ${ }^{45}$ Notice also that Ockham's revision makes future particular contradictory pairs obey RCP. Given the strong evidence in Int. 9 that Aristotle rejects RCP for future particular contradictory pairs, we should not be tempted to think that Aristotle is (contra Ockham's own interpretation of Aristotle) in fact adopting an Ockhamist account of truth. 
Ockham's interpretation of Aristotle on truth is consistent in the relevant respects with recent scholarship. ${ }^{46}$ On the dominant interpretations of Aristotle's account of truth, propositions (1) - (3) are inconsistent. Attributing to Aristotle an incoherent account should be an interpretation of last resort. But Whitaker's interpretation, on which Aristotle holds (1) - (3), requires us to do just this or to offer a revisionary account of Aristotle's general theory of truth, a project that appears unpromising. That the project is unpromising is evidenced not only by the fact that many good Aristotelian scholars have endorsed the dominant account, but more immediately is evidenced by the fact that our own reading of chapter nine turned up a good deal of evidence in favor of the dominant account. Most obviously, we have evidence in chapter nine that Aristotle endorses the claim that future particular contradictories cannot both be true, or both false. So, it must be the case that one is true and one false, or that they lack truth-values. But we also found Aristotle claiming that if a statement is true, then it is necessary (i.e., ineluctable). Since some future particular contradictory pairs contain no necessary statements, it must be that some future particular statements are neither true nor false. But if that is the case, then this must be because there is as yet no reality there to which they correspond or fail to correspond. Rejecting the claim that propositions (1) - (3) are inconsistent for Aristotle requires offering both a more plausible general account of Aristotle on truth than the dominant account offers, and a more compelling reading of chapter nine than the one I offered in the previous section. Even motivating the consideration of a new account will be difficult if it includes Whitaker's claim that

\footnotetext{
${ }^{46}$ See esp. Crivelli 2004 for an impressively comprehensive account. See also Michael White, 'Fatalism and Causal Determinism: An Aristotelian Essay', The Philosophical Quarterly 31 (1981), 231-241. White labels the view of time which he attributes to Aristotle the 'dynamic-present/past conception of time', according to which the future fundamentally lacks the reality of the present and the past. On the correspondence view of truth which accompanies this conception of time, "[the only] facts or states of affairs that there can be at a given time are those that are [present or past] at that time, and ... the only sort of correspondence relation that can obtain at a given time is correspondence at that time" (233).
} 
Aristotle accepts PBF but not RCPF, since it seems obvious that the negation of RCPF, together with the claim that future particular contradictory pairs cannot have either two true members or two false members, entails the negation of PBF.

If this is right, then we have reason to examine closely the three main lines of evidence Whitaker marshals in favor of his interpretation to see if they require it. I will examine each in turn, arguing that the evidence is inconclusive at best.

\subsubsection{Aristotle tacitly employs $P B F$}

First, Whitaker notes that PBF is tacitly employed in the argument from $18 \mathrm{~b} 17-25 .^{47}$ This, he claims, is evidence that Aristotle holds PBF; otherwise, it would be illegitimate for him to employ it in the argument. Indeed, I agree that it is illegitimate for Aristotle to employ premises that he does not accept, with the exception of the refutand and what follows from it. If a premise is employed by Aristotle but is not the refutand and does not follow from the refutand, ${ }^{48}$ then this provides good evidence that Aristotle accepts that premise. And I agree that Aristotle tacitly employs PBF here: The argument assumes that a statement that is not true is false. ${ }^{49}$ But this is not good evidence that Aristotle accepts PBF, for we have already seen (§3.1.2) that PBF follows in a straightforward way from RCPF and a principle to which Aristotle is clearly committed - that every statement has a contradictory. Since PBF follows from the refutand along with a principle Aristotle accepts, that Aristotle employs PBF is not good evidence that he accepts it. He may accept it, or he may reject it along with the refutand; we shall have to determine this on separate grounds.

\footnotetext{
${ }^{47}$ I discuss the argument in more detail in $\$ 3.1$, above.

${ }^{48}$ That is, does not follow from the refutand along with premises Aristotle accepts.

${ }^{49}$ See Whitaker 1996, 117-118.
} 


\subsubsection{Assertions are defined in terms of bivalence}

A second reason that Whitaker gives for thinking Aristotle holds PBF is that if we deny this, there seem to be textual inconsistencies both within De Interpretatione and elsewhere in the corpus. ${ }^{50}$ The internal textual inconsistency is the most important. Aristotle defines statements at Int. $4(16 \mathrm{~b} 33-17 \mathrm{a} 2)$ as "[sentences $(\lambda o ́ \gamma o \mathrm{o})]^{51}$ of which truth or falsity hold". If statements are by definition things of which truth or falsity hold, then future particular statements by definition satisfy PBF.

This is a troubling bit of text for those who would deny that Aristotle holds PBF, but it is not so troubling as it at first appears. First, it would not be shocking for Aristotle to make a statement and then qualify it later. But more importantly, in chapter four Aristotle is trying to distinguish between declarative sentences and other sentences like prayers. And surely future particular statements belong in the category of the former, rather than the latter. It is a little bothersome for the definition if truth or falsity do not hold now of a future particular statement, but truth or falsity is the sort of thing that will hold of such a statement. In perhaps anachronistic language, the proposition expressed by a future particular statement is the sort of thing of which truth or falsity can, and indeed will, hold, while a prayer is something which in principle cannot be true or false. While it is bothersome that we cannot always say that truth or falsity does hold of a future particular statement, as $16 \mathrm{~b} 33 \mathrm{ff}$ seems to imply, this bit of bother does not count decisively, or even strongly, for the view that Aristotle is committed to PBF. At any rate, it pales in comparison to the strong evidence we have encountered for the rejection of PBF.

\footnotetext{
${ }^{50}$ Ibid., 125-126.

51 'Phrases' would be better here than 'sentences' but for the fact that 'phrases' is often used in English in such a way as to exclude sentences. 'Sentences' serves the present purpose well, though we would do well to take more care with the translation were we working on Int. 4.
} 
Whitaker appeals to three texts outside of De Interpretatione. Categories 2a7-8 states, "It seems every affirmation is true or false." Here Aristotle is concerned to distinguish items in combination like 'man runs' from single items like 'man' and 'runs'. Only the former are true or false. Again, this can be given a similar treatment to Int. $16 \mathrm{~b} 33-17 \mathrm{a} 2$, for Aristotle is concerned with a particular sort of distinction and seems not to have future particular statements specifically in view. Another text is Metaphysics $\Gamma 1011 \mathrm{~b} 28$ : "One who says that something is or not will speak truly or falsely." But this text can easily enough be read in such a way as not to commit Aristotle to PBF, but only to the law of excluded middle. ${ }^{52}$ And finally, Whitaker appeals to De Anima 430b4-5, which reads: "But, then, it is not only false or true that Cleon is white, but also that he was or will be." ${ }^{53}$ This is evidence against Aristotle's denial of PBF, but it should not be overplayed. Aristotle is not always careful in his language or examples; it would not be too surprising, whatever his settled position, if he ascribed truth or falsity to 'Cleon will be white' in a passage where the truth or falsity of future particular statements is not the issue at hand.

What conclusions can we draw? First, each of the four passages can be read in such a way as to severely limit its force against the thesis that Aristotle denies PBF. Second, as I argued above (§3.1.1), much deeper aspects of Aristotle's thought, including his theory of truth, provide support for the view that Aristotle is committed to denying PBF, whether or not this view coheres well with every passing statement Aristotle makes. Indeed, this gives us reason to read these texts in a way that does not commit Aristotle to PBF, so far as possible. So, an appeal to texts

\footnotetext{
${ }^{52}$ On this, see Christopher Kirwan, Metaphysics Books $\Gamma, \Delta$, and E (2 ${ }^{\text {nd }}$ ed.), Oxford: Clarendon Press, 1993, p. 118. Kirwan argues that the text in question concerns Aristotle's commitment to the law of excluded middle, and denying bivalence for future particular statements does not commit one to denying excluded middle.

${ }^{53}$ Manuscript L omits the "will be", perhaps intentionally in an effort to remove the apparent contradiction with Int. 9.
} 
outside of Int. 9 has not yet been shown to provide decisive or even strong support for the thesis that Aristotle holds PBF.

\subsection{4 'But not yet true or false'}

A third reason Whitaker gives for thinking Aristotle holds PBF is more complex, but

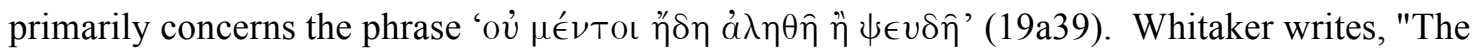
view that Aristotle denied truth value to future singular assertions rests principally on the interpretation of this phrase as 'not yet true or false'." ${ }^{54}$ At first look, this phrase does seem to point to a denial of PBF. But Whitaker gives three reasons to think that this interpretation of 19 a39 is "extremely unlikely". I shall consider each of these reasons in turn.

a) It cannot be the case that neither member of the contradictory pair is true, for this would not respect the constraint established at 18b17-25. At 18b17-25, Aristotle established that fatalism cannot be avoided by saying that neither member of a future contradictory pair is true, for then neither would occur. But if neither occurs, then there is no future at all, for one or the other must occur if there is a future. Whitaker takes care to point out that on his interpretation of Aristotle's explanation of the failure of RCPF to hold, this constraint is met. Though it is not settled which member is true and which is false, nevertheless one is true and one is false. ${ }^{55}$ So, it is not the case that neither is true. But if Aristotle's explanation is that PBF does not hold, it appears as if he does not respect his own constraint. This appears to count in favor of Whitaker's interpretation.

But this line of argument is misguided, for in fact Whitaker's interpretation fares worse with respect to this constraint. The trouble with Whitaker's interpretation is that it becomes very difficult to say with any clarity what it means for one member to be true and the other false, but

\footnotetext{
${ }^{54}$ Whitaker 1996, 123.

${ }^{55}$ Ibid., 124.
} 
neither to be determinately true or false, ${ }^{56}$ in a way that preserves PBF and respects the constraint of $18 \mathrm{~b} 17-25$. But the interpreter who thinks Aristotle denies PBF has a very simple explanation for why Aristotle fails to respect his own constraint: The constraint holds only when the refutand, $\mathrm{RCPF}$, is assumed. The constraint is expressed within the reductio argument. Recall that from RCPF and SC, PBF follows. And from PBF it follows that if neither member of a future particular contradictory pair is true, then both are false. And it is their falsity that entails that there will be no future, not their lack of truth value. ${ }^{57}$ By denying PBF Aristotle can avoid the constraint altogether, for it arises only if PBF is assumed. If in the end Aristotle denies rather than accepts PBF, this is more easily explicable with respect to $18 \mathrm{~b} 17-25$, not less.

b) The qualification 'but not yet true or false' is applied only to usual things, not to chance things. In Physics B.5, Aristotle recognizes three sorts of things: those that happen always, those that happen for the most part but not always, and those that happen neither always nor for the most part (i.e. by chance). These categories seem to be in view in the present chapter, particularly in 19a18-22. Whitaker finds these categories to be in view in 19a32-39. If 'not yet true or false' is a denial of bivalence, it should apply to both non-necessary classes of future particular statements. But Aristotle applies it only to the things that happen for the most part, not to those that happen neither always nor for the most part. If this were Aristotle's way of escaping the fatalist argument by denying PBF, it should apply to the latter class as well. It is best, then, to understand this as a denial of RCPF rather than PBF. ${ }^{58}$

\footnotetext{
${ }^{56}$ Note well that 'determinately' as a qualification for 'true' or 'false' has little to do with the thesis of determinism that is denied in Int. 9. Rather, if a statement is not determinately true or false, then the state of the world is such that it is genuinely up in the air whether or not the state of affairs it says will obtain will, in fact, obtain.

${ }^{57}$ Recall from $\$ 3.2 .2$ that Whitaker is committed to this and uses it to argue that Aristotle is committed to PBF. See Whitaker 1996, 117-118.

${ }^{58}$ See Whitaker 1996, 122-123.
} 
This argument is not very satisfying and there are several things to be said about it. First, it is not obvious that Aristotle means in 19a32-39 to distinguish between those non-necessary things that happen for the most part and those that do not. But, let us assume that he does. Still,

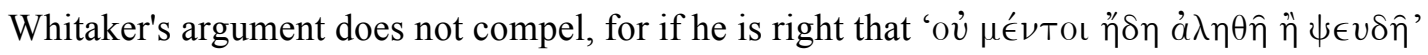
(19a39) applies only to things that happen for the most part, he is right whether this is interpreted as expressing the denial of RCPF or the denial of PBF. Yet Whitaker thinks that the denial of RCPF holds of both usual and chance statements. The emphasis of RCPF is important here because one might think (wrongly) that if, of a future particular contradictory pair $(p, q), p$ is usually so and $q$ is usually not, this allows us to assign truth to $p$ and falsity to $q$, thereby satisfying RCPF. But the same inclination would give Aristotle reason to emphasize PBF here: We might think that truth and falsity can be assigned to $p$ and $q$ if they are usual, thereby satisfying PBF, but not if they are neither necessary nor usual. Whitaker's reasoning does not aid us in deciding between the two interpretations.

c) "True or false" must simply be elliptical for RCP. Suppose we assume that Whitaker is correct about this interpretation of 19a39, though we have just established that this is questionable. What consequences does this have? First, it does not have the consequence that Aristotle accepts PBF. Aristotle's denial of PBF is compatible with this interpretation of 19a39. Second, it does not establish positive evidence for Whitaker's thesis that Aristotle explains the failure of RCPF to hold by claiming that, while one member of the pair is true and one is false, it is indeterminate which is which. Instead of providing positive evidence for this thesis, Whitaker's interpretation of 19a39 simply removes a piece of evidence which has sometimes been taken to be decisive in favor of the view that Aristotle denies PBF. Nevertheless, that Aristotle denies PBF is still on the table as a possible interpretation. Whitaker's arguments concerning "not yet true or false" do not in the end tell decisively in favor of his overall interpretation. Nor does the combination of his three main sources of evidence. 


\section{Conclusion}

I have argued not only for many particular details of interpretation in Int. 6-9, but also that the chapters are intimately connected. In particular, Int. 6-9 constitutes an examination of contradictory pairs and which sorts of them obey RCP, LEM, and PB. In each of chapters seven through nine, we find a counterexample to RCP. Contradictory pairs consisting of statements that are semantically many violate $\mathrm{RCP}$, and, in those cases where a single term represents two things that are not a unity, LEM. Contradictory pairs consisting of future particular statements violate RCP and PB. The analysis of future particular statements should be of particular interest, as chapter nine is one of the most widely discussed philosophical passages ever produced. I have demonstrated that the traditional conclusion that Aristotle denies PB for future particular statements is correct, though not because the passage has the argument structure it is generally thought to have. Rather, chapter nine continues to focus on RCP, even as it also rejects PB. ${ }^{59}$

\section{References}

Ackrill, J. L. 1963. Aristotle's Categories and De Interpretatione, Oxford.

Bobzien, S. 2008. 'Aristotle's De Interpretatione 8 is about Ambiguity', in Dominic Scott (ed.), Maieusis: Essays in Ancient Philosophy in Honour of Myles Burnyeat, Oxford, 301-321.

\footnotetext{
${ }^{59}$ In writing this essay, I have benefitted greatly from conversations with and comments from many people, among whom the following stand out: Dominic Bailey, Hugh Benson, Ray Elugardo, Hugh Hunter, John Mouracade, Christopher Shields, Robin Smith, and Linda Zagzebski. Earlier versions of parts of section 3 were presented at the 2008 Central Division Meeting of the American Philosophical Association and at the 2008 Alaskan Philosophy Workshop in Ancient Philosophy at the University of Alaska at Anchorage, where I benefitted from formal comments from Dean Kowalski and Mark Wheeler, respectively, and informal comments from a number of capable scholars. Most recently, an anonymous referee for this journal provided detailed comments which have resulted in a number of improvements.
} 
Cresswell, M. J. 2008. 'Does Every Proposition Have a Unique Contradictory?', Analysis 68, 112-114.

Crivelli, P. 2004. Aristotle on Truth, Cambridge.

Fine, G. 1984. 'Truth and Necessity in De Interpretatione 9', History of Philosophy Quarterly 1, 23-47.

Keefe, R. 2000. Theories of Vagueness, Cambridge.

Kirwan, C. 1993. Aristotle's Metaphysics Books $\Gamma, \Delta$, and E (2 ${ }^{\text {nd }}$ ed.), Clarendon Press, Oxford.

Ockham. 1983. Predestination, God's Foreknowledge, and Future Contingents, trans., with introduction, notes, and appendices, by Marilyn McCord Adams and Norman Kretzmann, Hackett.

Shields, C. 2007. Aristotle, Routledge.

Thomason, R. H. 1970. 'Indeterminist Time and Truth-Value Gaps', Theoria 36, 264-281.

Whitaker, C. W. A. 1996. Aristotle's De Interpretatione: Contradiction and Dialectic, Clarendon Press, Oxford.

White, M. 1981. 'Fatalism and Causal Determinism: An Aristotelian Essay', The Philosophical Quarterly 31, 231-241. 